Final diagnosis

Congenital haemangiopericytoma.
Keywords: haemangiopericytoma; orbit; proptosis; neonates
1 Stout AP, Murray MR. Haemangiopericytoma: a vascular tumour featuring Zimmerman's pericytes. Ann Surg 1942;116:26-33.

2 Bailey PV, Weber TR, Tracy TF, et al Congenital haemangiopericytoma: An unusual vascular neoplasm of infancy. Surgery 1993;114:936-41.

3 Depowski M, Maciejewski Z. Przypadek wrodzonego

haemangiopericytoma oczodolu. [Congenital idiopathic orbital haemangiopericytoma.] Patol Polska 1975;26:281-5.
4 Boyle J, Kennedy C, Berry J, Mott MG. Congenital haemangiopericytoma. $f R$ Soc Med 1985;78(suppl 11): 10-2.

5 Kaufman SL, Stout AP. Haemangiopericytoma in children. Cancer 1960;13:695-710.

\title{
Pyrexia, pancytopenia and macrophage inclusions in an elderly woman
}

\author{
J Robotis, C Christopoulos, A Tzavaras, I Gikonti, E Anevlavis
}

An 86-year-old woman presented with a 2-month history of intermittent fever up to $39^{\circ} \mathrm{C}$ associated with progressive weakness and wasting. On physical examination she was thin with no hepatosplenomegaly or lymphadenopathy. A full blood count showed haemoglobin $9.0 \mathrm{~g} / \mathrm{dl}$, white cell count $1.57 \times 10^{9} / 1$ and platelets $106 \times 10^{9} / 1$. Erythrocyte sedimentation rate was $70 \mathrm{~mm}$ in the first hour. Biochemical profile was within normal limits apart from polyclonal hypergammaglobulinaemia. Bone marrow aspiration was difficult, yielding a small haemodilute sample with only few nucleated cells. A trephine biopsy of the marrow is shown in the figure. Abdominal ultrasound examination showed the spleen to be present and of normal size.

Agia Olga Hospital, Athens, Greece First Department of Interna 1 Medicine J Robotis

C Christopoulos

A Tzavaras

E Anevlavis

Department of

Histopathology

I Gikonti

Correspondence to Dr C Christopoulos, Vas. Alexandrou 7, Kifissia, Athens, 14561 Greece

Accepted 10 March 1998

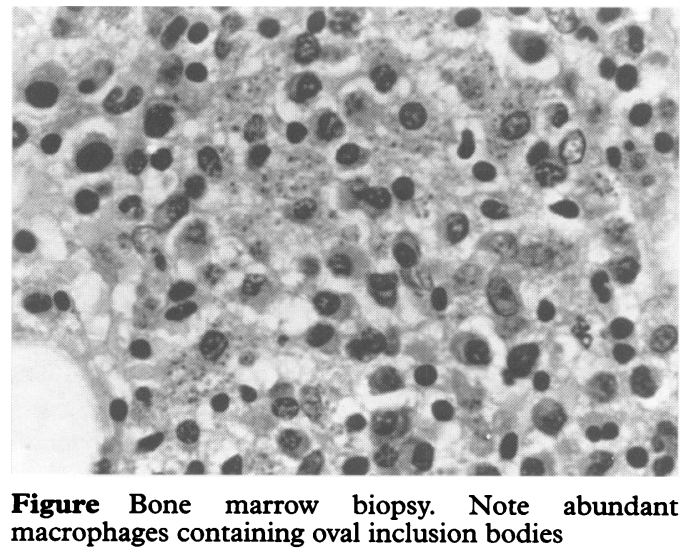

Questions

1 What is the diagnosis?

2 Name one auxiliary laboratory investigation.

3 How would you treat this condition? 


\section{Answers}

\section{QUESTION 1}

The trephine biopsy shows that the bone marrow is densely populated by macrophages, most of which contain large numbers of Leishman-Donovan bodies, a finding diagnostic of visceral leishmaniasis (kala-azar). There is also an excess of plasma cells, an associated histological finding characteristic of leishmaniasis. Bone marrow examination is the diagnostic method of choice, giving positive results in $80 \%$ of cases of symptomatic visceral leishmaniasis. ${ }^{1}$ Splenic aspiration has even higher sensitivity but is usually avoided for fear of bleeding.

\section{QUESTION 2}

Indirect evidence of infection can be provided by a variety of serological methods. In this patient, a complement-fixation test for leishmania antibodies was positive at a dilution of $1: 1600$. Most of these tests have acceptable sensitivity and are also useful in monitoring the response to treatment. False positives due to cross-reaction with antigens of other protozoa can occur. The leishmanin skin test of delayed hypersensitivity to injected killed parasites is typically negative in patients with active visceral leishmaniasis and becomes positive following successful treatment.

\section{QUESTION 3}

The standard first-line treatment of kala-azar is with one of the pentavalent antimonial compounds (sodium stibogluconate or $N$-methylglucamine) administered parenterally daily for at least 20 days. Treatment failures are sufficiently common in certain geographic areas including the Mediterranean and effective alternative drugs are available, the most commonly used being amphotericin-B and pentamidine. ${ }^{2}$ Our patient was treated with conventional doses of intramuscular pentavalent antimonium for one month and showed a good initial response with disappearance of the pyrexia and normalisation of the blood counts. A few months later the pyrexia and pancytopenia returned and a relapse of visceral leishmaniasis was confirmed by bone marrow examination. This time the patient was treated with

1 Manson-Bahr PEC. Diagnosis. In: Peters W, KillickKendrick $\mathrm{R}$, eds. The leishmaniases in biology and medicine, Vol 2. New York: Academic Press, 1987; pp 703-29.

2 Berman JD. Chemotherapy for leishmaniasis: biochemical mechanisms, clinical efficacy, and future strategies. Rev Infect Dis 1988;10:560-86.

3 Rees PH, Kager PA. Visceral leishmaniasis and post-kalaazar dermal leishmaniasis. In: Peters W, Killick-Kendrick R, eds. The leishmaniases in biology and medicine, Vol 2. New York: Academic Press, 1987; pp 583-615.

\section{Learning points}

- normal size of the spleen does not exclude advanced visceral leishmaniasis

- treatment with liposomal amphotericin-B can be well tolerated even by debilitated elderly patients

amphotericin-B and, in order to minimise toxicity, the liposomal formulation of the drug $\left(\right.$ Ambisome ${ }^{R}$ ) was employed at a dose of 2 $\mathrm{mg} / \mathrm{kg}$ daily intravenously for 21 days. This was well tolerated and led to clinical and haematological remission, which lasted until her death of a myocardial infarction 8 months after completion of treatment.

\section{Discussion}

Splenomegaly, often massive, is the feature which usually prompts the clinician to search for visceral leishmaniasis in patients who reside in, or have travelled to, endemic areas and present with fever and anaemia or pancytopenia. Although the spleen can be of normal size early in the course of the infection, ${ }^{3}$ it is considerably enlarged by the time the haematological abnormalities have appeared. The reason for the striking absence of splenic enlargement in this patient with florid visceral leishmaniasis is not known. Functional asplenia of old age is a possibility. ${ }^{4}$ It is worth noting that splenomegaly is frequently absent in visceral leishmaniasis occurring in the immunocompromised host, ${ }^{5}$ an entity that includes the debilitated elderly individual. The case presented here demonstrates that absence of splenic enlargement in a pyrexial, pancytopenic, elderly patient should not mislead the clinician to overlook the possibility of visceral leishmaniasis, which, if untreated, is usually fatal.

\section{Final diagnosis}

Visceral leishmaniasis.

Keywords: leishmaniasis; pancytopenia; fever; liposomal amphotericin

4 Zago MA, Figueiredo MS, Covas DT, Bottura C. Aspects of splenic hypofunction in old age. Klin Wochenschr 1985;63: 590-2.

5 Fernandez-Guerrero ML, Aguado JM, Buzon L, et al. Visceral leishmaniasis in immunocompromised host. $A m \mathcal{F}$ Med 1987;83:1098-102. 